\title{
IS NATIVE TITLE LAW DESTROYING NATIVE TITLE?
}

\author{
KATE GALLOWAY \\ Associate Lecturer \\ James Cook University School of Law
}

\author{
Notes of a paper delivered as part of the \\ Native Title Seminar Series \\ for \\ Native Title Studies Centre \\ James Cook University \\ Cairns
}

26 April 2006 


\section{Is Native Title Law Destroying Native Title?}

Today I'm going to share with you some of my observations of the native title process over the past couple of years, during which time I practised as a lawyer in a native title representative body. I share these reflections to encourage a critical perspective on native title processes and on the practice of law. In particular, I seek to show through this critical perspective that rather than recognising and protecting native title, native title law is in fact destroying native title. I will argue that it takes this critical perspective to understand the impact our dominant system has on traditional rights and interests.

In my address today, I will examine the role of the law, the role of the lawyer, the role of the anthropologist and the role of the parties in the native title claim process. I will suggest that all of these players collude within this system to deconstruct traditional culture, thereby possibly turning it into something else. It is on this basis that I suggest that the native title processes perform an almost assimilationist role and that all parties to these processes are complicit in this. The process of assimilation denies the identity of traditional rights and interests as being of their own unique system, and claims them as part of the dominant paradigm.

I will be using the term 'assimilation' to imply that a subordinate group comes to 'accept and internalise values and culture of the dominant group'. In contrast I will use 'multiculturalism' to imply allowing a group 'to live along side [a dominant group] while adhering to its own values'. ${ }^{1}$ While traditional owners themselves may not feel that they have internalised the values of the dominant group, today I will explore the idea that to prove culture, to prove identity, to prove connection according to the norms of the dominant system, is effectively to submit to that system and become of that system - if not least in the eyes of the dominant system itself. Once the dominant system categorises traditional law as 'native title' in accordance with its norms, the traditional body of laws becomes 'native title' and is a creature of common law. Traditional law exists no longer on its own terms: it has been destroyed.

\footnotetext{
${ }^{1}$ John Scott \& Gordon Marshall (eds) A Dictionary of Sociology (3 ${ }^{\text {rd }}$ ed, 2005) 24. 


\section{The Common Law}

Pre-Mabo, ${ }^{2}$ the Australian courts could not conceive of an indigenous claim to land as a property right. An oft-stated example of this is Milirrpum v Nabalco:

I think this problem has to be solved by considering the substance of proprietary interests rather than their outward indicia. I think that property, in its many forms, generally implies the right to use or enjoy, the right to exclude others, and the right to alienate. I do not say that all these rights must co-exist before there can be a proprietary interest or deny that each of them may be subject to qualifications. ... [B]y this standard, I do not think that I can characterise the relationship of the clan to the land as proprietary. ${ }^{3}$

It was within the framework of property that the common law sought to understand the nature of the relationship between people and land. In spite of parallels within the feudal tenurial system where services were expected of those who held an interest in land, the experience of the dominant legal culture failed to recognize in customary law any parallel with its own norms. And underlying this are the unasked questions: why did indigenous claims need to be categorized as a property right; and why should the colonial courts need to find parallels in common law.

In Mabo however, the court was ready to recognize customary law reflecting the relationship between people and land, and found a way to admit it into the common law without disturbing Australia's claim to sovereignty.

The case put by the Meriam people in Mabo, using the common law, was a subversion of the legal conceptual framework hitherto applied in Australia in favour of the settlers. Mabo sought to achieve an outcome achieved for traditional owners elsewhere in the world - using the dominant system to further their own ends. There was no suggestion that in using the common law the applicants actually came to 'accept and internalise the values and culture of the dominant group' ${ }^{4}$ ie the action brought by the Meriam people was not an act of assimilation, but arguably represented more a desire to live alongside the dominant culture while adhering to their own values (which could be described as a

\footnotetext{
${ }^{2}$ Mabo v The State of Queensland (No 2) (1992) 175 CLR 1.

${ }^{3}$ (1971) 17 FLR 141, 268-73, Blackburn J.

${ }^{4}$ John Scott \& Gordon Marshall Oxford Dictionary of Sociology (3 ${ }^{\text {rd }}$ ed, 2005) 24. 
multicultural approach). In legal argument, they did not seek to challenge the sovereignty of the dominant group, but sought to stand alongside the dominant culture within its broad framework. Importantly also, the court did not seek to absorb the traditional law and custom of the Meriam people: it did not destroy their native title but recognised it as a separate system. As a result of their action, the Meriam people became a people whose own laws were recognized by common law.

(It should be noted that a precondition for success was not to challenge sovereignty, which the High Court found was not justiciable. This does represent working within the dominant framework, but does not necessarily represent acceptance or internalisation of it.)

What the common law did recognise seems to have been a unique set of rights derived from customary or traditional law. The nature of native title as sui generis has been accepted by the Australian courts - for example:

\footnotetext{
Native title has its origin in and is given its content by the traditional laws acknowledged by and the traditional customs observed by the indigenous inhabitants of a territory. The nature and incidents of native title must be ascertained as a matter of fact by reference to those laws and customs. $^{5}$
}

Native title has its origin in the traditional laws acknowledged and the customs observed by the indigenous people who possess the native title. ${ }^{6}$

Mabo [No 2] was a brave judicial attempt to redress the wrongs of dispossession. But its "recognition" of native title has involved the courts in categorising and charting the bounds of something that, being sui generis, really has no parallel in the common law. ${ }^{7}$

Richard Bartlett has argued that where the courts identify native title as having this unique nature (ie in term of the dominant paradigm) they impose a barrier to according native title 'full respect' under the law. ${ }^{8}$ This means that if native title is regarded as sui generis, the law can impose on traditional owners the burden of proving that the title

${ }^{5}$ Mabo v Queensland (No 2) (1992) 175 CLR 1 [64] per Brennan J.

${ }^{6}$ Fejo v Northern Territory (1998) 195 CLR 96 at [46] per Gleeson CJ, Gaudron, McHugh, Gummow, Hayne \& Callinan JJ citing Brennan J with approval.

${ }^{7}$ Western Australia $v$ Ward (2002) 191 ALR 1, [969] per Callinan J.

${ }^{8}$ Richard Bartlett Native Title in Australia ( $2^{\text {nd }}$ ed, 2004) 102. 
exists. The recent case of Risk $v$ Northern Territory of Australia ${ }^{9}$ illustrates the types of burden Bartlett talks about.

- First, traditional owners must particularise traditional laws and customs. In Risk, the judgment provides significant detail as to particular traditional laws and customs. It draws on historical documentary evidence, and on oral testimony of the applicants. There is a list of traditional laws and customs including cultural organisation and practices, economy and resource use, spirituality etc. The judgment, as is the way in our legal system, outlines the case for and against the existence of many of these traditional laws and customs. It is usual to see such detail in native title cases. One problem with this approach is the onus it places on applicants such as those in Risk, where indigenous people's lives and the practice of their customs have been disrupted as a consequence of European settlement. Another problem for applicants is that it is questionable the extent to which the laws of a traditional society can be particularised in terms the common law can understand. The problems with this are illustrated in the evidence given in the Kumarangk (Hindmarsh Island) Royal Commission, as outlined by Strelein ${ }^{10}$ where counsel assisting the commission said to George Trevorrow, giving evidence, 'I want to put a label on it so that we can understand it.' Ultimately the witness responded, 'It is plain to see you would never understand about that anyway.'

- Secondly, courts may refuse to recognise that a society must necessarily have maintained traditional laws and customs: if a group is a society, then it must have some system by which it achieves that cohesion. In Risk Mansfield J accepted 'The Larrakia community of today is a vibrant, dynamic society which embraces its history and traditions. This group has shown its strength as a community...' and 'that there is, and has been, a continuous recognition in the Darwin area of certain persons as Larrakia, both by self-identification and by community

\footnotetext{
9 [2006] FCA 404 (unreported, Mansfield J, 13 April 2006).

${ }^{10}$ Lisa Strelein 'The "Courts of the Conqueror": The Judicial System and The Assertion of Indigenous Peoples' Rights' [2000] Australian Indigenous Law Reporter 22
} 
recognition.' 11 The judge refers to the 'Larrakia people' throughout the judgment, although ultimately distinguishes this from the 'current' Larrakia society. In spite of acknowledging the applicants' identity as a people, the judge found nevertheless that there was no maintenance of traditional laws and customs. It is not clear then by what standard the applicant group was distinguishable as the 'Larrakia people'. Because the society was viewed through the dominant paradigm, it was denied existence: it seems to exist, but is not recognised. It is destroyed.

- Thirdly, the courts require proof of continued acknowledgement and observance of traditional laws and customs. Again, Mansfield $\mathrm{J}$ in Risk said that his 'focus [had] been upon whether the current Larrakia society has the traditional laws and customs of the society which existed at sovereignty.' Mansfield J found

\footnotetext{
'significant changes in those laws and customs from those which existed at sovereignty... [which were] not simply an adaptation or evolution of the traditional laws and customs of the Larrakia people in response to economic, environmental and historical and other changes'. ${ }^{12}$
}

While there was evidence in Risk of the applicants following traditional law or custom, the court found that there were inconsistencies in evidence as to what the law was, and in particular that there was not a traditional mode of oral transmission from elders. The Larrakia people had relied on external sources to learn about their laws and customs, and this was not (according to the court) a traditional means of dissemination. Mansfield therefore did 'not find that their current laws and customs are 'traditional' in the sense required by s 223(1) and as explained by the High Court in Yorta Yorta. ${ }^{13}$ This is in spite of the judge stipulating that the applicants had to show that 'the present day body of accepted laws and customs in essence is the same body of laws and customs acknowledged and observed by the ancestors of members of the Larrakia people adapted to

${ }^{11}$ Risk v Northern Territory of Australia [2006] FCA 404 (unreported, Mansfield J, 13 April 2006), [825].

12 ibid, [837].

13 ibid, [834]. 
modern circumstances. ${ }^{14}$ (emphasis added). He then added a further requirement, of showing that the 'system of rules... has had a continued existence and vitality since sovereignty". ${ }^{15}$

The current vitality of the applicants' culture was defeated in spite of its essential nature being retained and adapted as there was apparently no continued existence. Again this begs the question of how a continuous society can have a vital culture now, in the face of oppression and dispossession, if there has not been in essence a continuation of that culture.

- Fourthly, the law has rejected the concept that abandonment (of the traditional laws and customs) must be voluntary. This leaves applicants like those in Risk unable to defend the apparent discontinuous practise of the laws and customs enumerated, on the basis that it wasn't their choice. It also means that applicants like the Larrakia people are left unable to resuscitate elements of their culture through adaptive, external means (such as receiving knowledge of culture from people outside the clan) as this apparently is not a traditional mode of learning.

These burdens reinforce the identity of this title as the 'other' in our system: it 'is neither an institution of the common law nor a form of common law tenure but it is recognised by the common law'. ${ }^{16}$ As the 'other', falling outside the dominant paradigm, the dominant system in its new (post-Mabo) consciousness will recognise native title, but fails to give it form. In highlighting its unique and special nature, the courts have not given native title substance within their dominant system. In that respect, the system is destroying native title itself.

This prompts the question of whether it is the role of the common law to give native title substance, or whether it is simply its role to receive it as it is - or if you like, in common law terms laid down in Mabo, as a burden on the Crown's radical title. Native title after all represents 'the antecedent rights and interests in land possessed by the Indigenous

\footnotetext{
14 ibid, [8].

${ }^{15}$ ibid, [10].

${ }^{16}$ Fejo v Northern Territory (1998) 195 CLR 96 at [46] per Gleeson CJ, Gaudron, McHugh, Gummow, Hayne and Callinan JJ.
} 
inhabitants of the territory [which] survived the change in sovereignty ${ }^{, 17}-$ ie it was here first, and it is the job of the common law to fit in with what previously existed. This is supported by the judgement of Gleeson CJ, Gaudron, Gummow and Hayne JJ, in Commonwealth $v$ Yarmirr where they said:

Because native title has its origin in traditional laws and customs, and is neither an institution of the common law nor a form of common law tenure, it is necessary to curb the tendency (perhaps inevitable and natural) to conduct an inquiry about the existence of native title rights and interests in the language of the common law property lawyer. ${ }^{18}$

However in the following year in Western Australia v Ward, Gleeson CJ, Gaudron, Gummow and Hayne JJ described the task as 'identifying how rights and interests possessed under traditional law and custom can properly find expression in common law terms'. 19

If the dominant law could allow native title substance, native title may enter the common law property rights discourse. This would however require a full description of native title within the framework of common law property rights. Janice Gray argues that 'the task of recognition is made easier if the unknown is equated with the known' ${ }^{20}$ However she also points out that 'we will need to explore more creative means for giving expression to Indigenous customs and traditions if they are unfamiliar to the common law, 21

The comments in Western Australia v Ward could be seen through a bigger lens as suggested by Gray: that 'properly finding expression' implies something more creative than a mere translation which would involve these rights losing their identity (ie being destroyed). Such an approach could represent the difference between assimilation of Aboriginal and Torres Strait Islander culture, and a multicultural solution.

\footnotetext{
${ }^{17}$ Mabo v Queensland (No 2) (1992) 175 CLR 1 at 57 per Brennan J at 82-3, cited in Bartlett see above $n 1$. ${ }^{18}$ [2001] HCA 56 (Unreported, Gleeson CJ, Gaudron, McHugh, Gummow, Kirby, Hayne and Callinan JJ 11 October 2001), [11].

19 [2002] HCA 28 (Unreported, Gleeson CJ, Gaudron, McHugh, Gummow, Kirby, Hayne and Callinan JJ 31 October 2002), [89].

${ }^{20}$ Janice Gray 'Is Native Title a Proprietary Right?' (2002) vol 9, No3 Murdoch University Electronic Journal of Law [7].

${ }^{21}$ Ibid, [14]. 
These concepts could perhaps be advanced if it were not for the Native Title Act, which directly intervenes in the common law processes to interpose its own administrative process into native title.

\section{The Native Title Act}

The enactment of the Native Title Act 1993 (Cth) ('NTA') and its subsequent interpretation by the courts changed the position of traditional owners from their Mabo foundation. The Act seeks to 'recognise and protect native title'. ${ }^{22}$ It purports to work for the benefit of Aboriginal peoples and Torres Strait Islanders - indeed the preamble recites that the Act is a special measure for the 'adequate advancement and protection of Aboriginal peoples and Torres Strait Islanders' in terms of the International Convention on the Elimination of All forms of Racial Discrimination.

However this aim fails to identify how advancement will be achieved: how the 'just and proper ascertainment of native title rights and interests' cited in the preamble will advance Indigenous Australians. One analysis may assume that this is through the integration of Aboriginal peoples and Torres Strait Islanders into the dominant culture. This is affirmed by the Act's charter to 'recognise and protect' native title - the dominant culture being the protector.

A traditional owner however may see advancement as the right to exercise their traditional laws and customs to the fullest extent, free from interference by the dominant culture.

What is the reality? I argue that the application of common law processes in the courts and government policy view 'advancement' within the dominant paradigm, which creates a point of difference for Aboriginal and Torres Strait Islander peoples. From this perspective, the Act captures and regulates the process by which advancement was apparently achieved under common law by the Meriam people in Mabo. It wrests control of the common law process undertaken in Mabo and submits it to the requirements of the statute even though it is anticipated (and indeed required) that the court

${ }^{22} \mathrm{~s} 10$. 
moderate/determine every claim. This process transforms traditional law and custom into common law recognised rights.

Rather than traditional owners using the dominant system to advance their customary law position which I argue reflects a multicultural perspective, the Act now brings the customary law system within the hybrid administrative and judicial processes of the Native Title Act in such a way as to assimilate traditional law and culture. The impact of the way the Act is used has been seen in our discussion of the Risk case - in particular in the burden of proof borne by claimants to particularise their traditional law and custom and to show that they have continuously observed it since sovereignty.

Callinan $\mathrm{J}$ in Ward acknowledges the challenges posed by the Act:

\begin{abstract}
'Parliament has been compelled to intervene, repeatedly, to secure the validity of acts that were never before thought to be problematic. And we now have a body of law that is so complicated, shifting and abstruse that it continues to require the intervention of this Court to resolve even the most basic issues, such as the effect of freehold or leases on native title. Judging from the submissions to this Court and the native title legislation that we have had to consider, few people, if any, have been able to thread this labyrinth of Minos unscathed.' ${ }^{23}$ (footnotes omitted)
\end{abstract}

Rather than address the direct legal aspects of the Act in any further detail, I will look at the application of government policy through funding of native title issues under the Act.

\title{
The Funding Aspects of the Native Title Act
}

The Commonwealth actively controls the native title process through funding: not applicants directly, but via native title representative bodies ('NTRBs') as well as funding respondents, National Native Title Tribunal and courts. It also passively controls the process through the knowledge that state governments will fight claims via the adversarial court system.

In addition, the Commonwealth exercises passive control via requirements for accountability of NTRB's to the Commonwealth for the funding. Funding is tied up with 'outcomes' determined by the Commonwealth. These are not the outcomes of 'adequate

${ }^{23}$ Ward v Western Australia (2002) 191 ALR 1, [969]. 
advancement and protection of Aboriginal peoples and Torres Strait Islanders' or 'full recognition and status within the Australian nation to which their prior rights and interests...entitle them to aspire' recited in the Act's preamble. Rather these are outcomes in terms of those NTRB functions enumerated in s203B NTA and the terms of the NTRB funding agreement.

The definition of the outcomes by which accountability is measured confirms the analysis that the dominant paradigm determines what is 'adequate advancement and protection of Aboriginal peoples and Torres Strait Islanders'. The relevant Commonwealth department would surely report that the Act was achieving its objectives if its own threshold were met. Whether the people for whose benefit the Act is in force would agree is not part of the assessment process. Indeed the formal reporting requirements and audit processes imposed on NTRB's by the funding bodies leave little if any scope for reporting outside the funder-determined outcomes. The perspective of Indigenous people is omitted altogether from the funding framework.

This funding process, instigated by the NTA, fails to 'recognise and protect' native title. It fails to take into account traditional law and custom and it dictates the method of operation of organisations charged with facilitating the native title process for applicants. It views the native title process, native title law, through a dominant paradigm unconnected to the traditional rights and interests. To this extent, the funding process itself contributes to the dismantling of native title as traditional law, and promotes the dominant understanding of what is native title.

\section{Joinder of parties}

As mentioned, the funding framework extends beyond NTRB's (on behalf of applicants) and to respondent parties.

It seems that the sui generis nature of native title (whose identity as a common law proprietary interest is questioned) broadens the base of those who would normally have standing to challenge a claim for land: for respondents do not need to show an interest in land. Thus people who would not have standing in a common law claim relating to 
protection of their real interest, have standing in native title jurisdiction. Respondent parties eligible to be funded under s200 and s183 NTA include:

- the state, which has sovereignty and which claims full beneficial ownership (s200);

- local authorities whose power is derived from the state and which have no estate nor interest in land under their jurisdiction (unless they hold crown land as trustees, in which case their interest is on behalf of the crown);

- miners whose rights are derived from the state which owns all minerals;

- commercial fishermen whose rights are derived from the state or Commonwealth;

- $\quad$ pastoralists whose rights are derived from the state ; and

- trespassers whose claims to crown land would not be entertained at common law.

In Risk, the respondent parties included: Darwin City Council, Amateur Fishermen's Association of the Northern Territory, Conservation Land Council, Darwin Model Flying Club and the Northern Territory Christian Schools Association.

Except in respect of the states, the Attorney-General's guidelines for funding require the respondent to show it is reasonable that the action be funded. This includes considerations such as:

- the severity and the extent of the implications of the native title claim for the applicant;

- what will happen if the [applicant] does not have a chance to put forward their views;

- whether the benefit to the applicant is worth the cost of the case; 
- the benefit the general public will gain from obtaining a decision in the matter. ${ }^{24}$ In addition, the guidelines acknowledge that 'not having legal representation is likely to create a detriment (emotional, business management and financial) for individual parties' ${ }^{25}$ These elements therefore are implicit in every application. There is no such acknowledgement in the NTA preamble, in spite of its reference to justice and advancement of Aboriginal peoples and Torres Strait Islanders.

Nowhere in the guidelines is there any mention of recognition or protection of native title. There is no indication of any burden of proof on the applicant in relation to establishing an interest in the land claimed. The guidelines appear to support government-funded obstacles to achieving recognition and protection of a pre-existing right. If we know that native title exists, which was established in Mabo and affirmed in the $N T A$, surely it's a matter for the state to establish that its unequivocal exercise of sovereign power has extinguished native title in any particular case ie that the state establish where it has the full beneficial ownership of land. This would indeed '[advance] and [protect] Aboriginal peoples and Torres Strait Islanders' and provide 'full recognition and status within the Australian nation to which their prior rights and interests...entitle them to aspire' as recited in the Act's preamble.

The whole tenor of the NTA however places the onus on applicants to prove their prior interest, in contest with respondent parties funded by the agency with a responsibility to protect that interest. In not just allowing but in funding the variety of respondents that it does, the government (passively) ensures that the recognition process can only occur where the respondent parties allow it to do so. Respondents are usually willing to allow this in exchange for concessions from native title holders. Respondents' bargaining power is strongest before recognition takes place. This process, of which traditional owners are by definition a part, inhibits or defers recognition and protection of native title.

\footnotetext{
${ }^{24}$ Attorney-General's Department, Legal Aid Branch, Provision of Financial Assistance by the AttorneyGeneral in Native Title Cases Guidelines (30 November 1998) < http://www.ag.gov.au/agd/WWW/agdHome.nsf/Page/RWPCF4E5D9BB8F1D8DFCA25705E0082A471> at 8 April 2006, clause 6.5 .

${ }^{25}$ ibid, clause 6.6. 
A more beneficial reading of the legislation or even application of the funding processes may acknowledge that if the state has granted rights which were subject to other (ie customary) rights and interests, then those interest holders will take only what the state was able to give. This is a matter as between the state and other interest holders. This issue is not one for traditional owners to engage in.

As beneficial legislation, the NTA should be read in favour of native title holders. ${ }^{26}$ Indeed in Commonwealth $v$ Yarmirr, ${ }^{27}$ the court found that:

\begin{abstract}
In so far as the act provides for protection of native title it can be seen as supplementing the rights and interests of native title holders under the common law of Australia and thus in this way at least, giving effect to one of the purposes of the Act recorded in its preamble. ${ }^{28}$
\end{abstract}

Note that the Act supplements rights. This means, it is in addition to existing rights. This is at odds with the scheme of the Act which, as we have seen, seeks to establish that those rights exist. Creating the adversarial environment in which this is established, including support for respondent parties where it is a 'matter of public interest' that a determination of rights (impliedly of the respondent) be made, surely does not supplement these rights of native title holders but rather seeks to challenge them.

The scheme implemented by the NTA creates a forum within which traditional owners are required to exercise the state's standard of proof to satisfy the state and respondent parties, and to negotiate away full native title rights simply to have those rights recognized and protected by the common law. The Act itself thus provides a mechanism for the rights' destruction.

When we look at this legislation through our ethnocentric lens, in spite of what the courts have declared in relation to native title, all we can see is the imposition of the unknown, the other, onto the known, the familiar of our existing norm of common law derived real property rights. This position is clearly reflected in the scheme of the Act, and in its application.

\footnotetext{
${ }^{26}$ Pareroultja $v$ Tickner (1993) 42 FCR 32 at 44 per Lockhart J (O'Loughlin and Whitlam JJ in accord).

${ }^{27}$ (2001) 208 CLR 1.

${ }^{28}$ at [7]. 
Traditional owners and their pre-existing rights remain marginalised unless and until the common law can conceive of them within its own framework in accordance with the procedures in the NTA. At this point, the common law takes ownership of those rights as their protector.

\section{The Lawyer}

We have browsed through some of the common law and statutory aspects of native title to identify where traditional law and custom is effectively usurped and thus destroyed by the dominant paradigm. We'll turn now to examine where the lawyer stands in this process. There are three main threads we'll look at: the repackaging of traditional owner knowledge as evidence; identifying the lawyer's duty to the traditional owner client; and obtaining informed consent.

Lawyers are after all officers of the court. Their overarching duty is to the court. This duty supersedes any duty to their client. Lawyers are part of the legal system, and a product of it. This is where I am interested to explore the dual relationship between lawyers and traditional owners, and lawyers and the system - which we have seen is skewed apparently against the traditional owner, in spite of the declarations in the case law and in the Native Title Act itself. I argue that by engaging in the native title process, in applying the craft of a lawyer, lawyers too are complicit in the deconstruction and assimilation of traditional owners' culture into the dominant culture.

\section{Repackaging Traditional Owner Knowledge}

In the 1979 film Kramer vs Kramer, ${ }^{29}$ the Dustin Hoffman character admitted to his estranged wife that he had felt responsible for their son's accident in a playground. Both parents came together when the son was being treated for his injuries, and engaged in a tender exchange. Later in the courtroom custody battle, the father was cross examined by the mother's counsel about the playground incident. "Didn't you admit to feeling responsible when your son was injured?" This evidence was adduced to indicate that the father was not suitable to take custody of the child. The Meryl Streep character looked

${ }^{29}$ Directed by Robert Benton, Columbia Pictures Corporation, 1979. 
crestfallen: she had obviously disclosed the incident to her lawyer without realizing the potential for it to be used against the father.

This scenario illustrates how lawyers use evidence. It shows that to a lawyer, your story, your identity, your feelings, are all available to support your case in court. It shows that once this enters the public domain, it changes the nature and character of the story or identity or feeling. It also shows how a client can lose control, lose ownership of their story.

I feel this is a useful analogy for native title. Lawyers are trained to collect evidence, select the best and present it in support of their client's case. For a traditional owner client, identity and culture provide the evidence for a native title claim and in giving that evidence over, it changes things as it did in Kramer vs Kramer.

Lawyers therefore have an entirely different concept of traditional culture. To a lawyer, regardless of their respect for or commitment to traditional owners' struggle to get their land back, the stories, activities and culture of traditional owners constitute evidence in an adversarial trial. These activities and stories will be evidence in support of the claim, or they will be evidence against the claim. For the NTRB lawyer, in the latter case this 'evidence' must be explained either in terms which bring it within the framework supporting the claim, or at least as not destroying the integrity of the claim (ie when the state or another respondent party raises this issue, how can we answer their claims?).

Crown representatives too should use information about activities and stories judiciously in their interactions with traditional owners. Comments to traditional owners in mediation, such as 'you don't even have a language any more' to imply that connection is weak are disrespectful at best, and at worst reveal the attitude of the dominant paradigm (the state) towards the traditional owner. Such a view is incorrect at law, but as a guiding philosophy represents the passive dismantling of traditional culture by the native title lawyer.

I am of the view that lawyers need to recognise the way they handle information and knowledge in the native title context, and take care in how they use it. Gaining 
information about how a person or a group of people behave from time to time, can be intrusive and handled insensitively can disempower the person. This flies in the face of the goal in the preamble of the NTA.

\section{Lawyers' Duty to the Traditional Owner Client}

We can envisage an inherent clash of culture with the NTRB lawyer in the same terms as that between traditional and common law itself, where the lawyer naturally translates native title into common law concepts. This is necessary to oppose respondents' claims and answer their criticisms, as much as to find a concrete and substantial interest in common law terms, to maximise the benefit to their clients. The lawyer thinks: if I can find some kind of right to exclusive use and occupation of land, this is the biggest kind of right known to the common law, and we can secure a better and more extensive form of title for the traditional owners.

As discussed, this can deny a traditional owner their own conceptions of their native title rights and interests, and risks a ranking of native title rights and interests according to common law perceptions of proprietary interests. It has the related impact in relation to prioritisation of claims, again according to the funding framework. If a right can be characterised as one of a fuller extent (eg right to exclusive use and occupation) then that right will be pursued in preference perhaps to one which is characterised as a lesser right (eg right to pass over land seasonally). This does not necessarily reflect the priorities of traditional owners themselves.

This highlights why the legal profession in native title law must allow traditional owners to retain ownership and expression of their own laws and customs. To highlight the lawyer's duty to their client we must also consider the beneficial nature of the NTA and indeed of the premise on which Brennan J's judgment rested in Mabo:

...no case can command unquestioning adherence if the rule it expresses seriously offends the values of justice and human rights (especially equality before the law) which are aspirations of the contemporary Australian legal system. ${ }^{30}$

${ }^{30}$ Mabo v Queensland (No 2) (1992) 175 CLR 1 per Brennan J [29]. 
If the court itself is declaring the paramountcy of values of justice and human rights and equality before the law, a lawyer, in terms of the common law and the Native Title Act, will arguably have a duty to advance the self determination of their client or at least give expression in their argument to justice and human rights. This duty may well also extend to respondent lawyers who would need to present their own case in terms of the justice and human rights framework. Instead native title cases are presented in terms of proprietary interests and conceptions of lists of traditional customs observed by outsiders which serve to erode the place of traditional owners within the dominant paradigm.

I would argue that it is the duty of every lawyer to promote the self-determination of their client - regardless of the forum in which the lawyer is acting for that client but particularly so within an area identified with human rights, as is native title. To act with integrity, the lawyer must ensure that their client is in an informed position from which to make decisions in their best interests, or which at least advance what the client perceives to be their best interests. It is the duty of the lawyer to ascertain what those client perceptions are, and to identify how they can best be met by the law as it exists. The lawyer is at the interface of the system of customary law of the traditional owner, and the common law. To achieve the aims set out in the preamble of the NTA the lawyer must provide the means by which traditional owners' custom and knowledge and feelings are presented as an independent system adhering to its own values. If a lawyer presents the knowledge repackaged by the dominant system in terms foreign to the applicants interpreted by non-Indigenous lawyers and anthropologists, or presented in the way done by the defence in Kramer vs Kramer, this represents assimilation. This repackaging denies the voice of the traditional owner in their terms, and implies to the court and therefore at law, that the traditional owners have accepted and internalised the values and culture of the dominant group.

In the old school, a lawyer was the expert and the client simply did what they were told. This is no longer appropriate. A lawyer must get informed instructions. If the client is unaware of the stages in the legal process, their prospects of success and the consequences of failure, and how client information is used, then the client is marginalised by the process representing the dominant culture. 


\section{Stages in the Process}

Information about native title processes will empower traditional owners to the extent that they are more familiar with the processes imposed upon them, and therefore have the opportunity to become more engaged in these processes. In my experience traditional owners are more keen than clients for whom I have acted in other fields, to engage actively with all aspects of the process. I have for example taken for granted a directions hearing and its administrative nature, and failed to invite my clients to attend. This represented my view of legal process as administrative, of little substance and of a routine nature. My view failed to appreciate the empowering effect of active participation in legal processes on my clients. In addition, if my clients followed my lead of accepting processes as simply part of the system without my deliberate raising of my own and my clients' consciousness about the processes, the law and the tactics, they may run the risk of passively internalising this system thereby becoming part of it.

I have seen how in the focus on land rights and the (common) law, people become goal oriented and ignore the steps taken to achieve that end. This inevitably means that they are subsumed by the process. This is where NTRB lawyers must be vigilant to maintain their clients' voice: if they fail to give voice to what is important to their client at each step of the process, the dominant system becomes accepted as the new norm.

In reality many traditional owners I have met continue to question the processes and system. However their voices are not heard and there is no process in the courts for these voices genuinely to be heard. Their lawyers work within the system, they are of the system, and they themselves often do not hear. In failing to listen to these voices, and where lawyers fail to present this perspective in the context of native title processes, there will be an ongoing assumption by the participants in the system that the traditional owners do submit to the processes, and that they have internalised the values and culture of the dominant culture. This is then detrimental to a party who is required to show that in fact they adhere to an alternative system of norms and traditions and culture. This contributes to the destruction of native title, as recognised by the dominant system.

Prospects of Success 
The corollary to the NTA's process of recognition and protection of native title is that if the court finds there are no native title rights and interests, the claimant group has no standing in the eyes of the common law as the people of that land - that is, in the eyes of the dominant group. This is in stark contrast to how the traditional owners would perceive themselves, within their own norms. (Norms which the common law has declared do not exist.) This represents the dominant system purporting to assimilate the minority regardless of their self-perception - ie the destruction of native title.

The lawyer, I would submit, has a vital role in declaring to their client the consequences for the group if the claim were not successful and the prospects for success of the claim. In theory, it is then a matter for the group to elect whether or not to proceed, and the basis on which it will proceed. The process in which the group then elects to participate may well be one which alters the concept of traditional law by bringing it within the ambit of the common law. However where choice is exercised, it represents more an adaptation by traditional owners rather than a usurping by the dominant paradigm. Where lawyers fail to appraise their clients of the true prospects, they remove that choice and leave traditional owners to the system.

\section{Client Evidence}

As part of the process and prospects, claimants need particularly to be informed about connection, which requires the greatest amount and variety of evidence a lot of which may be sensitive if not confidential. The duty must be to properly inform the client of the place of connection in the scheme of the native title claim and how the knowledge of the traditional owners, presented in the connection report, will or may be used in the proceedings. The stakes here are very high and often traditional owners are not appraised of the downsides of providing information to support their claim. These downsides are that the state (or another respondent) will test the evidence, and that the court may find that it does not support the claim, as occurred in Risk. This is the common law saying that a people has extinguished their own rights and interests in land so that the common law 
will not recognise them. The court is saying that there is no genuine ongoing traditional and customary connection with land with its source in pre-European times.

If lawyers fail to put traditional owner clients in a position where the client appreciates how their knowledge is being used, lawyers run the risk not only of disempowering their client, but also of devaluing traditional culture and knowledge. This is done passively, through use of what is not the lawyer's, without express consent. The lawyer will use the lens of their own experience and take for granted that the information of the client, the traditional owner, is evidence and use it accordingly. This implies that the traditional owner has internalised the values and culture of the dominant system. Again, this implication leaves the members of the dominant system believing that traditional owners are of the dominant system, where this may not be the case. This perception undermines the culture and experience of the traditional owner, and indeed again, may ultimately change the nature of culture and knowledge where it intersects with the dominant culture.

\section{Informed Consent \& Proper Instructions}

Providing appropriate information and proper disclosure of risks to traditional owner clients is not assimilation, rather it is the opposite. Traditional owners are not asked to internalise these values and culture. Rather it brings the common law to the client in terms that the client can understand, so as to allow the client to use that system on their own terms. This is one responsibility of the lawyer.

This is really only ensuring informed consent from clients. If the client is properly informed then the lawyer not only obtains informed consent, but contributes to the selfdetermination of the client. A related issue to informed consent is taking proper instructions - and this is an area fraught with challenges for the native title lawyer.

The courts take care to ensure that actions undertaken on behalf of claimant groups are authorised. But authorised according to whose norms? Many lawyers fail to question the basis on which they take instructions even in simple matters involving only two or three clients and they often make assumptions about how best to communicate with clients even in simple matters which are not complicated by language, culture, literacy, 
remoteness, regularity of lifestyle or access to the tools of modern communication (including sometimes even the telephone).

If native title lawyers set up processes based on genuine client instructions involving say a steering committee or a committee of elders, and other people join the group or turn up purporting to represent another member, the lawyer is often not in a position to evaluate whether this alteration accords with instructions. While long-time lawyers with intimate knowledge of the group involved and its processes would be able to make an assessment, others will not.

It is vital for lawyers to take proper instructions early on - again in the interests of empowerment of their traditional owner clients - to ensure proper reporting and communication processes. Applying common law norms of authority may not work with a traditional owner group and this needs to be sorted out from the outset. Failure to do so implicitly imposes on the group the dominant norms. Yet again though, the lawyer faces the conflict between promoting clients' self-determination and giving voice to traditional law and custom, and the imposition by the system of the dominant norms. This can be illustrated by the Federal Court's increasing reliance on timetables in native title claims and the proliferation of traditional owner incorporated bodies.

The courts are becoming tougher imposing deadlines and timetables in native title cases and this impacts on authorisation meetings and meetings generally. Groups are often dispersed over wide areas; members often live in remote areas sometimes isolated for months due to weather; and a death in a community may cause a lengthy delay in all land business. Funding is always an issue. Timetables will not always be able to cater for these contingencies, yet failure to cater for them puts to one side the claimants' traditional way of doing business. I am aware of an important authorisation meeting where key people were absent. The cost of the meeting was well over $\$ 10,000$ (plus time involved in putting it together). The lawyer was nearly apoplectic at the absence - until they realised that it was due to the practice of avoidance rules. The upside for the lawyer was that this provided evidence of a normative system of rules. But the meeting ostensibly failed the dominant norm as to obtaining valid instructions. 
Secondly, it is noted that traditional owner groups around the country have formed incorporated associations for any number of purposes - promoting arts language and culture, promoting land issues, receiving royalties, or to be a prescribed body corporate under the NTA. Most NTRB's are aboriginal corporations incorporated under the Aboriginal Councils and Associations Act 1976 (Cth). Incorporation is often required by law before benefits can be received. Many corporations are set up within the common law but according to traditional decision-making structures. However for any number of reasons, the formal decision-making structures may be set up otherwise. That will not necessarily preclude traditional decision-making from taking place but so far as the common law is concerned, the documents of incorporation will be definitive.

While the establishment of such a body may provide the lawyers with evidence of modern application of traditional decision-making, it also may not. In Risk the court found that the entity making the decisions for the Larrakia people was Larrakia Nation Aboriginal Corporation. '[I]ts composition [was] not traditional' however as it was not universally accepted by all families, it was a democratic process and there was no evidence of involvement of a 'superior elder reflecting the sort of status reported by the 'King' figures referred to in earlier literature'. The court did 'not consider that process reflects the carrying on of the traditional method of decision-making by the Larrakia people'. ${ }^{31}$ While on the one hand often being required (by the dominant paradigm) to use modern decision-making structures, applicants on the other hand risk presenting to the court a departure from traditional law and custom. In the case of the Larrakia, the burden of proving that their decision-making was undertaken in a traditional way was too great.

This places a duty on the native title lawyer to think carefully about taking instructions and setting up traditional owner corporations. The real seat of power may in fact be elsewhere. To the extent that traditional owners use modern corporate structures, they run the risk of failing the native title test. The dominant norms are simultaneously applied to traditional owners, yet where traditional owners conform to dominant norms, they are seen as assimilated to the dominant culture and their own culture is denied.

\footnotetext{
${ }^{31}$ Risk v Northern Territory [2006] FCA 404 (unreported, Mansfield J, 13 April 2006) [832]. 
I would suggest that it is the duty of the practitioner, in particular when acting for a client who is part of a disempowered group in society, to ascertain the client's expectations and to inform the client as to the realistic prospects of success as well as the risks inherent in the process. Callinan J acknowledged in Ward that: '[t]o these drawbacks flowing from the recognition of native title may be added others ... I fear, the expectations of the indigenous people have been raised and dashed, ${ }^{32}$

The process of taking proper instructions and giving a client information to achieve informed consent will also give the lawyer information about the values and attitudes of the client. These must be given voice to avoid the imputation of those in the dominant culture that traditional owners have submitted themselves to the system and that they have impliedly internalised its values.

\section{The Anthropologist}

Having explored the lawyer's place in the native title scheme, we will briefly look at the anthropologist. One of the challenges in native title law is finding the evidence considered acceptable to the court and the respondent parties, to support the claim. The courts have to date relied on expert evidence and on reports written by early European witnesses to Indigenous culture.

Interestingly, this evidence is that of non-indigenous people. Logic would dictate that the experts on a traditional system of culture and law would be the people who practise that system and know it intimately yet traditional owners themselves are not necessarily called on to give expert evidence. Their statements and activities however may be reported on by an anthropologist in support of the expert evidence given by that anthropologist.

The position of the anthropologist is problematic. As a discipline, anthropology traditionally looks at a traditional society through the lens of the dominant culture. While the discipline has its own methodology (or methodologies) whose validity I do not challenge, it seeks to document a society through the observation and analysis of an

${ }^{32}$ Ward v Western Australia (2002) 191 ALR 1, [969]. 
outsider. Unlike the concept of traditional owners as the 'other' in dominant Australian culture and law, the anthropologist as the 'other' in a traditional system, is an empowered being. They may leave at any time and are not at risk of internalising values and culture to the rejection of their own, so as to be assimilated into the traditional culture.

Like the lawyer, the information, the knowledge and stories the anthropologist takes away inherently become something else, divorced from the people to whom they belong. In addition, the methodologies of the anthropologist are applied to the information, knowledge and stories to form the intellectual property of the anthropologist. However scientific the methodology, this is the lens of the dominant culture and logically the understanding we receive of traditional culture is a product of the methodology, not of the culture itself.

This is a filtering process which packages the traditional law and customs on which the court ultimately decides. It is possible that this package will be what the common law accepts or rejects as the foundation of a people's rights and interests. The traditional culture is therefore subsumed by the common law, based on the anthropologist's analysis.

Apart from methodology, the fact of the outsider's presence in the traditional context will inevitably skew the image received. This is an issue dealt with inherently within the discipline, but it is problematic for the courts to receive this very particular perspective in the context of a native title claim, and it is problematic for the anthropologist to engage in this process, presenting a non-traditional version of a traditional system. We return to Janice Gray's comment: 'the task of recognition is made easier if the unknown is equated with the known'. ${ }^{33}$ Perhaps this is the role of the anthropologist: as an intermediary between the dominant and the 'other'.

The danger here though is that through this process, declaring rights and interests based on the 'expert's' report, the culture and knowledge and tradition of the traditional owner is assimilated into the dominant culture. So far as the anthropologist works within this framework, the anthropologist will be complicit, with the lawyer and the legal system, in

\footnotetext{
${ }^{33}$ Janice Gray 'Is Native Title a Proprietary Right?' (2002) vol 9, No3 Murdoch University Electronic Journal of Law [7]. 
rendering traditional knowledge and culture as deriving its validity of the dominant. The real voice of the traditional owner is absent - present only through an agent's interpretation.

To the extent that the anthropologist works outside the framework, the evidence may lose its relevance. In Risk the Northern Territory challenged the weight of the evidence of the historian engaged by the applicants' NTRB on the basis 'of her alleged 'bias' or predisposition in favour of the ....applicants [and] ...not all historians would approach the exercise using her methodology'. ${ }^{34}$

The system is again placing the onus on applicants to deliver a package of evidence in terms and a form acceptable to the dominant norms. Expert witnesses like anthropologists are caught in the system themselves where to engage will almost certainly contribute to the reduction of traditional law and custom to a commodity for the courtroom, far removed from its true place. On the arguments I have put so far, this effectively dispossesses the traditional owners of their stories so that they become of the common law system. This represents a covert assimilation of traditional culture in the eyes of the dominant.

\section{Conclusion}

In this reflection I have attempted to raise the consciousness of practitioners in the field. It is incumbent on each practitioner, regardless of expertise, to reflect on how they practise, how they are instruments of the dominant culture - and how this impacts on their clients, traditional owners. A lack of awareness will draw them into the processes which in turn relentlessly pull traditional law and custom into the gravity field of the common law, and the dominant culture.

Native title law is destroying native title on a number of fronts. The NTA for all its talk of justice and advancement fails to articulate how this is achieved. Instead it establishes a series of norms to measure whether it considers native title even exists.

${ }^{34}[120]$. 
The courts, in identifying native title as sui generis, have failed to give it substance and the NTA fails to allow processes by which traditional owners themselves are able to do so. Where this process accepts native title exists, it becomes part of the common law and loses its unique nature. The list of rights and interests, intelligible to the common law, is enumerated and that is what is protected. Native title in its traditional sense is destroyed.

Where the process rejects native title, traditional owners have nothing recognised by common law. They are dispossessed forever of their rights. Their native title is destroyed.

This process of destruction is a form of assimilation aided and abetted by lawyers and anthropologists where in good faith they use the dominant paradigm to present their own version of traditional rights and interests. To the extent that these practitioners fail to engage traditional owners in the process and to give true voice to the claimants, the traditional law, custom and knowledge is lost to the traditional owners and is again usurped by the system. At every turn there is dismantling of what the common law sees as native title.

Is all lost? Practitioners in the field have a duty to raise the human rights element of native title, and to properly inform their clients. Full and proper engagement in the system is the only way to restore some little power to claimants. The Commonwealth as funder has a duty to give voice to traditional owners within the claim and funding processes. Like respondent lawyers, they also have a duty to handle their claims in a way which reflects the underlying goals of the NTA.

It will be with one voice, calling for recognition of human rights and true advancement of Aboriginal peoples and Torres Strait Islanders, that traditional native title rights and interest will be ascertained in a just and proper manner that has due regard for their unique character. Without this voice, the NTA and native title law are mere puff and will guarantee the destruction of native title as it was decreed in Mabo.

It was Callinan $\mathrm{J}$ in Ward $v$ Western Australia, who sums up the state of native title law and its interpretation: 
'[i]t might have been better to redress the wrongs of dispossession by a true and unqualified settlement of lands or money than by an ultimately futile or unsatisfactory, in my respectful opinion, attempt to fold native title rights into the common law. ${ }^{35}$ (emphasis added)

35 (2002) 191 ALR 1, [970]. 